\title{
DINÂMICA DE CURTO PRAZO DO DESMATAMENTO DA AMAZÔNIA LEGAL: ANÁLISE DO PAPEL DAS POLÍTICAS PÚBLICAS NO PERÍODO DE 2000 A 2010
}

\author{
Marcelo Bentes Diniz * \\ Márcia Jucá Teixeira Diniz ${ }^{\dagger}$ \\ Almir Bittencourt da Silva $\ddagger$ \\ Jorge EduARdo MACEDo Simões $\S$
}

\begin{abstract}
Resumo
Discute-se, em um contexto de um painel dinâmico, GMM-SYSTEM, os determinantes de curto prazo na dinâmica do desmatamento na Amazônia Legal no período de 2000 a 2010, ao encontro de testar o papel das políticas públicas relacionadas ao controle do desmatamento e a política de assentamentos destinados à Reforma Agrária na região. As evidências encontradas confirmam a importância da política regulatória no controle do desmatamento, enquanto a política de assentamentos mostrou-se não significante.
\end{abstract}

Palavras-chave: desmatamento; assentamento; regulação ambiental; Amazônia; GMM-SYSTEM

\begin{abstract}
This paper discusses, in a context of a dynamic panel, called the GMMSYSTEM, the short-term determinants of deforestation dynamics in the Legal Amazon from 2000 to 2010, in order to test the role of public policies related to the control of deforestation and the policy of settlements for Agrarian Reform in the region. The evidence found confirms the importance of the regulatory policy in controlling deforestation, while the settlement policy was not significant.
\end{abstract}

Keywords: deforestation, settlement, environmental regulation, Amazon, GMM-SYSTEM

JEL classification: Q56, R52, C22.

DOI: http : / / dx.doi .org/10.11606/1980-5330/ea141292

\footnotetext{
* Professor Associado FACECON/PPGE/ICSA/UFPA. E-mail: mbdiniz2007@hotmail.com

† Professora Associada FACECON/PPGE/ICSA/UFPA. E-mail: marciadz2012@hotmail.com

‡ Professor Titular FEEAC/CAEN/UFC. E-mail: almir@caen.ufc.br

$\S$ Professor Adjunto FACE/IEDAR/UNIFESSPA. E-mail: jsimoesf@yahoo.br
} 


\section{Introdução}

Existe uma vasta literatura empírica acerca dos determinantes do desmatamento, seja em escala mundial, regional ou, especificamente, em relação à Panamazônia ou Amazônia Legal brasileira.

Em uma tentativa de realizar um survey acerca das diferentes causas do desmatamento, que atingem as regiões de florestas tropicais no planeta, Geist \& Lambin (2001) defendem que é preciso entender as forças que explicam o padrão e mudanças nas taxas de transformação ambiental a partir de forças motrizes (driving forces) que agem globalmente e regionalmente, isto é, em um país ou grupo de países restrito ou mesmo em um grupo de estados dentro de um mesmo país ${ }^{1}$.

Dentro do framework apresentado pelos autores, existiriam causas imediatas (proximate causes), que seriam as atividades humanas (usos da terra) que diretamente afetam (fisicamente) o meio ambiente e assim constituem a fonte primária de mudança da cobertura da terra. Nesse grupo, em consonância com outros estudos Lambin (1994), Kaimowitz \& Angelsen (1998), seria possível identificar três causas agregadas próximas: expansão agrícola, extração de madeira e a expansão da infraestrutura.

Haveria, ainda, um segundo grupo de driving forces sugerido pelos autores, denominado de causas subjacentes (underlying causes). Forças motrizes subjacentes são entendidas como elementos fundamentais na sustentação das causas primárias do desmatamento. Elas podem ser vistas como um complexo de variáveis sociais, políticas, econômicas, tecnológicas e culturais que constituem condições iniciais nas relações humano-ambientais que têm um caráter estrutural (ou sistêmico). Aqui apareceriam, também, os determinantes, que seriam resultado de políticas públicas.

Do ponto de vista geográfico, coexistiriam padrões gerais de desmatamento, em termos de causas comuns, mas também padrões próprios, circunscritos a certas espacialidades, como identificado por Hecht (2012), para a América Latina e Caribe, porém, existiriam fatores-específicos relevantes de cada país em particular Scrieciu (2007).

Em relação à Amazônia brasileira, o crescimento do desmatamento é explicado pela expansão da fronteira agropecuária, liderada em um primeiro momento pela pecuária e depois pela agricultura mecanizada, particularmente a soja. Ademais, essas atividades econômicas, seriam potencializadas pela criação de infraestrutura física de transporte e logística e de outros fatores, que concorreram para a elevação de suas produtividades e, por consequência, de suas rentabilidades relativas frente a outras regiões do país ou atividades produtivas na própria região, inclusive, em decorrência de efeitos de políticas públicas implantadas na região.

Para a pecuária, Margulis (2003) demonstrou que a taxa de retorno dessa atividade na região Amazônica a partir da década de 1990 não só era positiva, como também era relativamente elevada frente a outras alternativas de uso da terra, incluindo as mais sustentáveis que implicavam em manejo florestal. Ademais, a sustentação dessa rentabilidade seria resultado da combinação de uma série de fatores, como: criação de novas áreas de pasto, motivado pelo crescimento do preço do boi gordo; crédito subsidiado baseado no Fundo

\footnotetext{
${ }^{1}$ É claro que, no âmbito do Brasil, o regional pode abranger o local, isto é, forças que incidem em um município, ou grupo específico de municípios.
} 
Constitucional Norte (FNO); uso gratuito de terras públicas; aumento da produtividade da atividade a partir da introdução de mudanças tecnológicas; e o papel do controle da febre aftosa Barreto (2008).

O crescimento da soja na região é atribuído desde condições edafoclimáticas $^{2}$ favoráveis, inclusive, a mecanização Domingues \& Bermann (2012) e o apoio do governo a partir de programas especiais direcionados ao setor e estímulos ao mercado de soja Mueller (1992), mas também, relacionadas à possibilidade de aproveitamento de áreas de transição cerrado-floresta ou terras degradadas Mueller \& Bustamante (2002), em um processo que comunga da expansão da própria pecuária em um ciclo de autorreprodução complementar, em que o sojeiro compra as áreas degradadas de fazendeiros de menor porte, obrigando-os a procurar novas áreas e alargar essa fronteira Fearnside (2006).

Também contribuíram para o crescimento da soja na região, entre o final do século XX e a primeira metade da primeira década do século XXI, fatores como: o crescimento da demanda internacional de soja, conjugada com a desvalorização cambial ocorrida no período Nepstad et al. (2008), o baixo custo das terras Castro (2005) e a melhoria de infraestrutura de transporte e logística Diaz-Balteiro et al. (2006), Nepstad et al. (2008), Domingues \& Bermann (2012), como, por exemplo, a criação dos portos em Itacoatiara e Santarém.

Entre 2004 e 2013, a Amazônia Legal brasileira ${ }^{3}$ experimentou uma queda relativamente contínua do desmatamento, cujo resultado é muitas vezes atribuído a uma melhora da eficiência dos instrumentos de fiscalização, monitoramento e controle do desmatamento nesse período Initiative et al. (n.d.), Ferreira \& Coelho (2015). Não obstante, seja aparentemente contraditória a política continuada de Assentamentos da Reforma Agrária nesse período, cujas evidências apontadas por estudos como de Brandão Jr \& Souza Jr (2006), Le Tourneau \& BurszTyn (2010), Alencar et al. (2015) apontam uma correlação positiva com o desmatamento na região. Diante do exposto, pode-se perguntar: qual o impacto que mudanças institucionais recentes relacionadas às políticas públicas de comando e controle e, ao mesmo tempo, voltadas à promoção da Reforma Agrária (Assentamentos), tiveram sobre a dinâmica de curto prazo do desmatamento na Amazônia Legal?

Procurando responder a essa indagação, esta pesquisa parte da hipótese de que as duas políticas mencionadas agem no sentido contrário: enquanto a política de comando e controle tem efeito redutor sobre o desmatamento, a política de assentamentos acaba por estimulá-lo.

Sob essa perspectiva, este artigo pretende discutir o processo recente de desmatamento na Amazônia Legal brasileira no período de 2000 e 2010, no qual a partir do uso de um painel dinâmico (GMM-SYSTEM) pretende-se investigar o comportamento das atividades apontadas como promotoras do desmatamento, em consonância com o impacto das políticas de comando e controle, e da política de assentamento (Reforma Agrária), além de outros fatores determinantes que possam ter contribuído para controlar ou estimular o desmatamento no período.

\footnotetext{
${ }^{2}$ Relativo ao solo e clima - (édafos de origem grega, significando fundação, chão, solo).

${ }^{3}$ Conceito político-administrativo instituído em 1953 (Lei 1.806), que define como limites territoriais a área dos estados da região Norte do Brasil: Acre, Amapá, Amazonas, Pará, Rondônia, Roraima e Tocantins e mais a integralidade do estado do Mato Grosso e parte do estado do Maranhão (Oeste do Meridiano de $44^{\circ}$ ). Perfaz cerca de 5 milhões de $\mathrm{km}^{2}$, correspondendo aproximadamente a 59\% do território do Brasil.
} 
Dentro dos objetivos mencionados, este artigo encontra-se estruturado em mais seis seções, além desta introdução. A segunda seção aborda os efeitos da política sobre o desmatamento na Amazônia. A seção três discute a metodologia empírica empregada no artigo. A seção quatro apresenta os resultados e discussões do modelo empírico. A quinta e última seção discorre acerca das considerações finais do artigo.

\section{Efeitos de Políticas Públicas sobre o Desmatamento na Amazônia}

\subsection{Efeitos de Incentivos}

A Floresta Amazônica, desde a década de 1960, tem passado por diversas formas de intervenção antrópica que provocam mudanças no uso e ocupação do solo na região, com impacto direto e indireto sobre o desmatamento. Existem fatores que podem ser ditos de caráter permanente como, por exemplo, a expansão da fronteira agropecuária, acompanhada ou não pela atividade madeireira. Além disso, existem determinantes de natureza transitória que reforçam ou potencializam a ação desses agentes ou drivers do desmatamento, como, por exemplo, os efeitos externos de políticas públicas relacionadas a incentivos fiscais; crédito subsidiado; infraestrutura de estradas e logística de produção; medidas fitossanitárias e tecnológicas que elevam a qualidade do rebanho e/ou das pastagens, com consequente aumento da produtividade da atividade; elevação dos preços das commodities; baixo custo da terra; entre outros.

De fato, fatores responsáveis pela melhora na rentabilidade dessas atividades na região ao longo do tempo, possibilitando redução de custos, ganhos de escala e acesso subsidiado a recursos de financiamento (capitalização dos produtores), vêm contribuindo de forma indireta para a evolução do desmatamento, ao mesmo tempo em que restrições impostas por políticas de comando e controle; regulação e legislação de uso e ocupação do solo impõem limites à sua expansão.

Em um dos estudos pioneiros para a região, Mahar (1979) acentua a importância que a política de incentivos fiscais teve para a expansão da pecuária na região na década de 1970, ao encontro de diminuir as vantagens comparativas negativas que a Amazônia tinha em termos de infraestrutura e distância aos principais mercados consumidores.

Para Mahar et al. (1989), o papel dos incentivos fiscais e de crédito subsidiado foi benéfico também à expansão da agricultura na década de 1970, como forma de compensar a sobrevalorização cambial, o controle de importações e outras políticas direcionadas à atividade industrial.

Hecht (1985) destaca como efeito adverso da política de incentivos fiscais para a Amazônia a corrida especulativa por terras como elemento que potencializou o desmatamento. Nessa direção, Fearnside (2006) reforça que os lucros especulativos da venda de terra chegaram a se constituir na principal fonte de renda dos fazendeiros na região, entre as décadas de 1970 e 1980, uma vez que os preços da terra subiam acima da inflação.

Para Reis \& Margulis (1991), as políticas governamentais que tiveram algum efeito sobre o desmatamento nas décadas de 1970 e 1980, além dos incentivos fiscais e creditícios foram: a criação da malha rodoviária e os programas de colonização. 
Para Walker et al. (2000), a importância da combinação de subsídio e crédito rural impulsionou a pecuária não só para os grandes produtores, em geral deslocados de outras regiões do país, mas também capitalizou os pequenos produtores que residiam na própria região.

Nepstad et al. (2001) observam que mais de dois terços das áreas desmatadas na Amazônia encontram-se a uma distância de $50 \mathrm{~km}$ das principais estradas pavimentadas na Amazônia, além de terem examinado os efeitos potencias da implantação do Projeto Avança Brasil, que previa um incremento de cerca de $50 \%$ das estradas pavimentadas na região na época. Para os autores, os efeitos seriam tanto diretos, com a possibilidade de conversão de grandes áreas de florestas ao longo das rodovias em plantações, pasto e floresta secundária, mas também, a partir de um efeito secundário, que seria derivado do crescimento da indústria madeireira e do incremento do inflamabilidade da floresta.

Reis \& Margulis (1991) foram um dos primeiros a introduzir um modelo empírico (econométrico) para verificar os determinantes do desmatamento na Amazônia. Os autores introduzem um modelo de equações simultâneas, em que o processo de desmatamento é pensado como resultado do "comportamento maximizador dentro de uma estrutura estática". Os modelos são estimados em uma estrutura Spatial Autocorrelation (SAC) e Seemingly Unrelated Regression (SURE) e constatam um efeito positivo e significante das estradas pavimentadas, enquanto das estradas não pavimentadas o efeito foi negativo sobre o desmatamento.

Pfaff (1999), para uma estrutura de um modelo pooled em nível municipal, para o período de 1978 a 1988, confirma um efeito significante e positivo da "densidade" das estradas pavimentadas e não pavimentadas, inclusive, um efeito de vizinhança das mesmas, mas também outros efeitos de política pública, como o relacionado à disponibilidade de crédito para infraestrutura e decorrentes dos projetos implantados medidos em termos da densidade espacial de sua área ocupada no município.

Weinhold \& Reis (2001) confirmam um efeito contemporâneo entre infraestrutura e população urbana para dois cortes temporais no ano de 1975 e 1985, entretanto, ao aplicar o teste de causalidade de Granger em uma análise em painel, concluem que é o crescimento da população que conduz ao desenvolvimento da infraestrutura e não o contrário. Ademais, a provisão de certas amenidades de infraestrutura poderia mesmo ter o efeito de reduzir a pressão sobre o desmatamento.

Andersen et al. (2002) são pioneiros em especificar um modelo para dados municipais ao encontro de tentar capturar um efeito dinâmico de variáveis endógenas defasadas no processo de desmatamento da Amazônia, considerando dois cortes temporais, um relativo ao crescimento entre 1980 e 1985 e outro referente ao crescimento entre 1985 e 1995. Todavia, ao contrário de outros estudos, no modelo para o período 1980-1985, os autores não encontraram significância estatística tanto em relação às transferências do governo federal para os municípios, quanto dos efeitos dos créditos oriundos do sistema FINAM, como também, em relação ao impacto da infraestrutura (estradas asfaltadas).

No modelo para o período de 1985 e 1995, o efeito das estradas foi bastante diferente. Os autores encontraram que tanto o efeito em nível, como da taxa de crescimento das estradas pavimentadas e não pavimentadas é positivo, 
sendo maior este feito, quanto menos desmatadas forem as áreas próximas dessas estradas.

Os efeitos das rodovias sobre o desmatamento ocorrem de forma direta pela área desmatada que dá lugar ao asfalto ou simples acesso, mas muito mais pelo seu efeito indireto, que ocorreu de diferentes formas. Existem evidências de um efeito de "proximidade" que as estradas exercem, aumentando as taxas desmatamento nas áreas do entorno das estradas, mas também em áreas adjacentes em que ocorre uma maior concentração das mesmas Pfaff et al. (2008). Um deles foi a elevação do grau de acessibilidade da região e a consequente redução dos custos de transporte, o outro foi a migração urbana.

Quanto às estradas não oficias, estas parecem ter forte vinculação com a mobilidade da atividade madeireira, cujos madeireiros ou extratores desbravam a mata na busca de espécies de maior valor Perz et al. (2007), Pfaff et al. (2008), mas também formam extensões de estradas alimentadoras, construídas na arquitetura dos projetos de colonização Walker et al. (2000).

Em linhas gerais, o efeito da infraestrutura pode ser pensado em dois momentos. Um efeito decorrente da associação direta, a exemplo da mata derrubada para a construção de estradas, barragens e criação de infraestrutura para projetos de assentamento, mas também por sua associação indireta ex-ante ou ex-post as obras. O efeito ex-ante ocorre pela atração de mão de obra durante a construção das obras, como no caso das hidroelétricas, além das economias externas criadas a outras atividades econômicas que exercem também efeito de atração sob a população de outros municípios. E o efeito ex-post, que ocorre muito em função da dinamização da economia municipal proporcionada pela obra no momento que adquirem condições de funcionamento, como também, da população que migrou e foi absorvida como mão de obra durante a obra, mas que passa a residir no município e cria outras atividades econômicas para sua sobrevivência. Além de potencializar, ainda, a atração para futuros imigrantes Reis \& Guzmán (1990), Fearnside (2006).

Também desde a década de 1970, vem sendo espaço para a colonização dirigida e assentos agrários, podendo essa região ser apontada como o principal locus de Reforma Agrária no país, tanto em termos do número de famílias assentadas, como da extensão da área com essa forma de ocupação Le Tourneau \& BurszTyn (2010). Como pode ser observado na Tabela 1, de forma acumulada até o ano de 2015, cerca de 70.706 mil hectares haviam sido destinados como assentamentos agrários na Amazônia Legal brasileira, abrigando 612 mil famílias (INCRA, 2016), não obstante com uma distribuição bastante desproporcional entre os estados. Ainda na tabela supracitada, em termos de área, os estados com maior participação nesse total foram o Amazonas $(37,64 \%)$ e o Pará $(23,53 \%)$, o primeiro, também, com maior média de hectares por família. Por sua vez, em termos do número de famílias assentadas, o estado do Pará lidera com uma participação percentual de $36,15 \%$, seguido do Maranhão com participação de 21,51\% e do Mato Grosso com 13,5\%.

Existem evidências empíricas de que a política de assentamentos, ou melhor, as atividades desenvolvidas pelas famílias assentadas, guarda um papel nada desprezível sobre o desmatamento Brandão Jr \& Souza Jr (2006), Le Tourneau \& BurszTyn (2010). Reunindo evidências entre 1970 e 2002, Brandão Jr \& Souza Jr (2006) apontam que nesse período os desmatamentos ocorridos nas áreas de assentamento representaram 15\% do desmatamento da Amazônia. Essa relevância das áreas de assentamentos no desmatamento total é corroborada mais recentemente por Alencar et al. (2015), que apontam que até 
Tabela 1: Número de famílias assentadas e área ocupada em hectares, entre as décadas de 1990, 2000 e 2010 2015

\begin{tabular}{|c|c|c|c|c|c|c|c|c|c|}
\hline \multirow{2}{*}{ UF } & \multicolumn{2}{|c|}{1990} & \multicolumn{2}{|c|}{2000} & \multicolumn{2}{|c|}{$2010-2015$} & \multicolumn{2}{|c|}{ Acumulado } & \multirow{2}{*}{ FA/há } \\
\hline & FA(1) & Área(há) & FA(1) & Área(há) & FA(1) & Área(há) & FA(1) & Área(há) & \\
\hline $\mathrm{RO}$ & 13.695 & 673.914 & 9.074 & 1.065 .343 & 2.112 & 1.159 .336 & 39.700 & 6.305 .361 & 158,83 \\
\hline $\mathrm{AC}$ & 8.234 & 471.986 & 12.925 & 4.195 .506 & 1.078 & 84.808 & 32.784 & 5.601 .623 & 170,86 \\
\hline $\mathrm{AM}$ & 7.585 & 790.855 & 39.310 & 24.941 .203 & 363 & 307.570 & 50.517 & 26.613 .190 & 526,82 \\
\hline $\mathrm{RO}$ & 7.266 & 546.307 & 4.702 & 460.650 & 76 & 4.038 & 14.763 & 1.281 .714 & 86,82 \\
\hline PA & 65.071 & 4.024 .464 & 134.262 & 8.633 .355 & 10.591 & 1.247 .569 & 221.269 & 16.639 .072 & 75,20 \\
\hline $\mathrm{AP}$ & 7.072 & 989.939 & 5.737 & 1.022 .565 & 1.012 & 81.835 & 14.761 & 2.226 .339 & 150,83 \\
\hline $\mathrm{TO}$ & 11.306 & 580.205 & 8.712 & 461.434 & 744 & 30.866 & 23.849 & 1.235 .475 & 51,80 \\
\hline MA & 65.728 & 2.019 .390 & 47.993 & 1.832 .277 & 5.500 & 208.320 & 131.630 & 4.735 .951 & 35,98 \\
\hline MT & 41.862 & 2.808 .685 & 25.652 & 1.943 .960 & 1.424 & 91.988 & 82.571 & 6.067 .509 & 73,48 \\
\hline $\mathrm{AL}(2)$ & & & & & & & 611.844 & 70.706 .236 & 115,56 \\
\hline
\end{tabular}


2014 ocorreu um desmatamento acumulado de 12,7 milhões de hectares nessas áreas, equivalente a $37 \%$ das áreas desses assentamentos e $40 \%$ da floresta presente originalmente nos mesmos, uma contribuição total ao desmatamento de $24 \%$ entre os anos de 2003 e 2010 e de $29,2 \%$ entre 2011 e 2014 .

Como chama atenção Alencar et al. (2015), para se ter uma real contribuição do desmatamento em áreas de assentamento é preciso descontar o passivo ambiental existente na data de sua criação, uma vez que a participação dos desmatamentos anteriores à criação dos assentamentos é bastante representativa nessas áreas. De fato, segundo estimativa dos autores, a porcentagem média de área desmatada por assentamento até a data de sua criação varia de $43 \%$ (seu maior valor) entre 2004-2008 a 33\% (seu menor valor) entre 20092014.

Importa dizer que, segundo estudos como de Alves \& Rocha (2010) Gasques et al. (2010), Helfand \& Pereira (2012) e Buainain \& Garcia (2013), os estabelecimentos rurais com área até 10 hectares, predominantemente de origem familiar, não conseguiam gerar renda agrícola acima do limite da linha da pobreza de $1 / 2$ salário mínimo per capita.

Ademais, como destacam Alves \& Rocha (2010), a estrutura agrária evidenciada pelo Censo Agropecuário de 2006 demonstrava uma forte dicotomia entre o número de estabelecimentos rurais por estrato de renda bruta mensal (em salário mínimo) e a renda bruta apropriada pelo mesmo. Assim, o estrato correspondente aos estabelecimentos rurais com renda bruta mensal maior de 200 salários mínimos, representavam $0,62 \%$ do total de estabelecimentos, mas se apropriavam de $51,19 \%$ da renda bruta gerada, enquanto que no polo oposto os estabelecimentos situados no estrato de renda bruta de até 2 salários mínimos mensais, embora significassem $66,01 \%$ do total de estabelecimentos, se apropriavam apenas de $3,27 \%$ da renda bruta gerada.

\subsection{Efeitos Restritivos}

Importa observar, também, que ao longo dos últimos trinta anos, ocorreram significativas mudanças no marco regulatório no uso das florestas, bem como na regulamentação ambiental voltada ao controle, monitoramento, fiscalização e combate ao desmatamento ilegal, cujas ações institucionais, denotam diferenças no grau de eficiência sobre a redução do desmatamento.

A Figura 1 mostra uma sequência cronológica da criação e implantação dessas ações institucionais (Criação do IBAMA, extinção da SUDAM) para potencialmente lidar com a questão ambiental, bem como ações mais específicas de comando e controle para reduzir o desmatamento ilegal - Programa de Prevenção e Controle de Queimadas e Incêndios Florestais na Amazônia Legal, Plano de Ação para Prevenção e Controle do Desmatamento da Amazônia Legal (PPCDAM), Operação Arco do Fogo, Operação Boi Pirata, Plano Amazônia Sustentável, Operação Onda Verde - ou ainda, a criação de marcos legais de atuação das atividades rurais (Decreto Lei $n^{\circ} 2.661$ que regulamenta o uso do fogo em práticas agropastoris e florestais, Lei de Crimes Ambientais, aumento da reserva legal, instituição do Cadastro Ambiental Rural) mostram uma trajetória que não explicita uma correlação bem definida com a evolução da taxa de desmatamento.

Dentre as iniciativas consideradas mais exitosas de combate ao desmatamento nesses últimos vinte anos está o Plano de Ação para Prevenção e Controle do Desmatamento na Amazônia Legal (PPCDAM) criado em 2004 e que 
Figura 1: Evolução do desmatamento na Amazônia Legal x aspectos institucionais de seu combate no período de 1988 a 2014

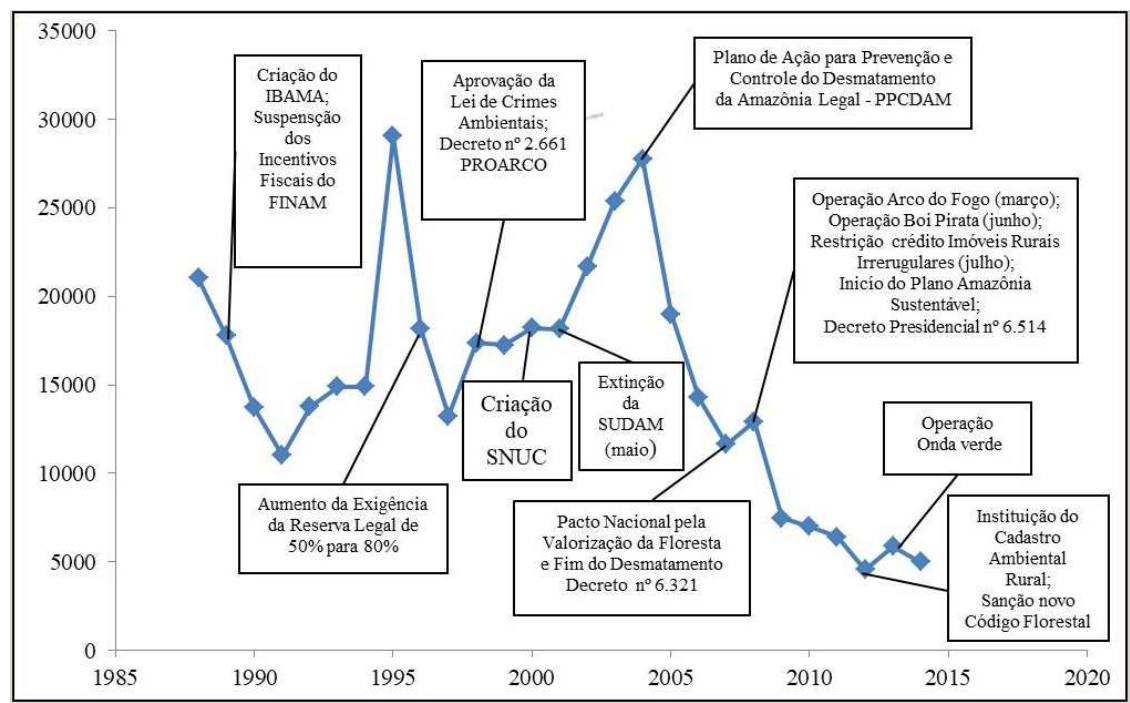

Fonte: PRODES/INPE, 2015. Elaboração dos autores.

foi implementado em três fases. A primeira fase, entre os anos de 2004-2008, centrou-se no Ordenamento Fundiário e Territorial, o que resultou na criação Unidades de Conservação Federais e Estaduais além da demarcação de terras indígenas. A segunda fase, entre os anos de 2009-2011, o eixo voltou-se, naquela oportunidade, ao Monitoramento e Controle, marcada por grandes operações integradas de fiscalização do desmatamento, em conjunto com o combate organizado, realizadas pelo IBAMA, Polícia Federal, e Força Nacional de Segurança Pública, além do apoio do exército brasileiro.

Contrasta na efetividade das ações institucionais a Lei de Crimes Ambientais em 1998, que não foi capaz de reduzir o desmatamento, ao contrário das ações derivadas do Plano de Ação para a Prevenção e Controle do Desmatamento da Amazônia Legal - PPCDAM, em 2004, que conseguiriam reduzir e manter uma trajetória de desmatamento a partir dessa data, reforçada por outras ações de controle mais ostensivo como as Operações Arco de Fogo, Boi Pirata, Onda Verde, entre outros. Além disso, o Decreto Presidencial $n^{\circ}$ 6.514, que instituiu pesadas multas ao descumprimento da Lei de Crimes Ambientais, pela não averbação em cartório por parte dos imóveis rurais da área destinada à reserva legal, parece que teve um efeito dúbio. Em um primeiro momento, entre 2008 e 2009, ocorreu um forte impacto redutor do desmatamento, mas à medida que aplicação das multas foi sendo adiada até o ano de 2012, data de sanção do novo Código Florestal, a política foi perdendo a credibilidade, resultando em menor poder redutor sobre a taxa do desmatamento.

Corroborando a análise, alguns estudos Assunção et al. (2015), Ferreira \& Coelho (2015) mostram que as políticas restritivas ao desmatamento (assentados em políticas de comando e controle) foram mais eficientes a partir de 2004, entretanto, é possível assinalar um grau de efetividade diferenciado entre os estados, sendo o estado do Mato Grosso aquele que logrou maior êxito entre os anos de 1999 a 2011.

Observa-se, entretanto, que a maioria dos assentamentos na Amazônia não 
são antigos, mas recentes ocorridos a partir de 1995, denotando que a política de colonização da região com o fim de destencionamento social perdura de forma estratégica como eixo da política nacional de desenvolvimento regional.

\section{Metodologia}

Ao encontro de verificar o efeito das mudanças institucionais sobre o desmatamento ocorridas na primeira década dos anos 2000, bem como testar outros efeitos da política pública, como da política de assentamentos para a Reforma Agrária ${ }^{4}$ ocorrida, também nesse período, será constituído um painel dinâmico de dados entre os anos de 2000 e 2010. O painel é balanceado tomando como unidade de observação os municípios dos estados da Amazônia Legal, para uma amostra com 743 observações, no qual foram considerados os municípios que constavam na base de dados do desmatamento do Prodes/INPE.

\subsection{Modelo Econométrico}

\section{Especificação do Modelo Econométrico}

A estimação de dados em painel organiza as observações em duas dimensões cross-sectional (corte transversal) e ao longo do tempo Wooldridge (2010). Assim, a especificação do modelo de painel dinâmico para a taxa de desmatamento pode ser expressa como:

$$
\begin{aligned}
\text { txdesmat }_{i t}= & \beta_{0} \text { txdesmat }_{i, t-1}+\beta_{1} \text { reg }_{i t}+\beta_{2} \text { efetbova }_{i t} \\
& +\beta_{3} \text { cultperm }_{i t}+\beta_{4} \text { cultemp }_{i t}+\beta_{5} \text { pib }_{i t} \\
& +\beta_{6} \text { pib }_{i, t-1}+\beta_{7} \text { pib }_{i, t-2}+\beta_{8} \text { fam }_{i t}+\beta_{9} \text { pnas }_{i t} \\
& +\beta_{10} \text { distcap }_{i t}+\beta_{11} \text { dens }_{i t}+\varepsilon_{i t} .
\end{aligned}
$$

Em que, $t x$ desmat $_{i t}$ é a taxa de desmatamento; $t x$ desmat $_{i, t-1}$ é a taxa de desmatamento defasada em um período; $r e g_{i t}$ é a regulação ambiental; ef etbova $a_{i t}$, cultperm $_{\text {it }}$ e culttemp $p_{i t}$ descrevem, respectivamente, a pecuária e as culturas permanente e temporária. O pib $b_{i t}$ representa o PIB per capita. As variáveis assentamento, pobreza, distância da capital e densidade demográfica são representadas, sequencialmente, por $f_{a m_{i t}}$, pnas $_{i t}$, distcap ${ }_{i t}$ e dens ${ }_{i t}$. $\varepsilon_{i t}$ é o termo de erro. Os subscritos $i$ e $t$ referem-se ao município no ano.

Espera-se que as variáveis: efetivo bovino por área do município (efetbova), área plantada com cultura permanente (cultperm) e área plantada com cultura temporária (culttemp), apresentem uma correlação positiva com o desmatamento, como demonstrado empiricamente em diversos estudos, como em Reis \& Guzmán (1990), Arima \& Uhl (1997), Weinhold \& Reis (2001), Arima (2001), Andersen et al. (2002), Arima et al. (2005), Diniz et al. (2009), Gazoni $\&$ Mota (2010), que apontam essas atividades como os principais drivers do desmatamento. Da mesma forma, espera-se que o aumento da densidade demográfica (dens), seja em decorrência do crescimento demográfico interno ou pelo movimento migratório, crie uma maior pressão e concorrência pelo uso e ocupação da terra, tendo por consequência o incremento do desmatamento Barreto et al. (2005), Diniz et al. (2009), Côrtes \& Oliveira (2014).

\footnotetext{
${ }^{4}$ No qual se testa, também, o efeito da incidência da pobreza sobre o desmatamento.
} 
Por outro lado, a variável distância da capital (distcap) guarda uma relação negativa com o desmatamento, uma vez que o efeito "isolamento" torna os municípios menos suscetíveis a capacidade de enforcement das políticas de comando e controle em reduzir o desmatamento. No entanto, Kaimowitz \& Angelsen (1998) chamam atenção que a acessibilidade, seja para a floresta ou para o mercado, é que define, do ponto de vista micro, o maior potencial de desmatamento dos agentes econômicos.

Considerando o efeito da política de assentamento, ( $\mathrm{fam}$ ) espera-se um efeito positivo sobre o desmatamento ao encontro de evidências reunidas por Brandão Jr \& Souza Jr (2006), Le Tourneau \& BurszTyn (2010), Alencar et al. (2015).

Com relação ao efeito da pobreza (pnas), estudos empíricos realizados, por exemplo, por Pearce \& Barbier (2000) e Markandya (2001), sustentam que não existem evidências empíricas suficientes que indique uma relação causal direta entre pobreza e degradação ambiental.

Para Wunder (2001), a evidência entre o nível de renda e a degradação ambiental é ambígua, podendo ser direta ou inversa, dependendo das especificidades de cada região. Segundo ele, a direção da relação dependeria da dotação de capital direcionado ao meio ambiente (indutor) relativo aos incentivos de retornos potenciais de outras atividades (redutor).

Todavia, estudos como de Geist \& Lambin (2001) e Chomitz et al. (2007) apontam a possibilidade do incremento do desmatamento como estratégia de sobrevivência e mitigação da condição de vida dos pobres, muito embora o estudo realizado por Finco et al. (2009) na área do chamado Cinturão Verde no estado do Tocantins confirme uma relação ambígua entre pobreza rural e desmatamento na região.

Portanto, em consonância com os resultados não conclusivos da literatura empírica, não se define aprioristicamente um sinal esperado para a determinação da pobreza (pnas) no contexto do modelo a ser estimado, podendo tanto ser positiva como negativa essa relação.

Quanto à variável regulação, especificada como uma variável dummy a partir do ano de 2004, em que se configura maior efetividade das políticas de comando e controle Assunção et al. (2015), Ferreira \& Coelho (2015), espera-se que esta apresente sinal negativo.

Por fim, a literatura empírica também constata uma regularidade empírica entre o crescimento da renda (medido pelo PIB per capita) e a degradação ambiental, que descreve uma trajetória de "U-invertido", denominada de Curva de Kuznets Ambiental Grossman \& Krueger (1995), Sachs \& Warner (1995, 2001), Stern (2004), Panayotou (2016). No Brasil, alguns estudos testaram a regularidade empírica da CKA entre crescimento e desmatamento, a exemplo de Santos et al. (2008), Gomes et al. (2008), cujas evidências encontradas corroboraram essa hipótese, enquanto que Oliveira et al. (2011), em um contexto de dependência espacial, constataram a presença de um formato de "N-invertido".

Observe-se, portanto, que foi a literatura empírica referenciada que levou a escolha das variáveis utilizadas no modelo empírico, cujas fontes, e respectivos sinais esperados em cada caso, encontram-se descrito na Tabela 2.

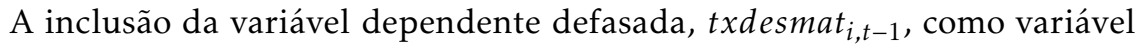
explicativa caracteriza o painel como sendo dinâmico. Entretanto, a utilização de mínimos quadrados ordinários (MQO), em modelos dessa natureza, 
fornece estimativas viesadas, em virtude de não lidar com a possível endogenia ${ }^{5}$ das variáveis explicativas, superestimando assim o parâmetro $\beta_{1}$.

Por outro lado, uma opção para contornar esse problema seria a utilização de um estimador de efeito fixo não observado dos municípios dos estados da Amazônia Legal, visando capturar a heterogeneidade individual. Podendo ainda, de modo análogo aderir ao método de Within Groups. Contudo, essa técnica fornece parâmetros inferiores aos de MQO, ou seja, subestima o parâmetro $\beta_{1}$, não obtendo êxito em expurgar totalmente a endogeneidade do modelo, permanecendo assim, o viés do painel dinâmico. Logo, uma estimativa não viesada de $\beta_{1}$ deve situar-se entre os limites dos estimadores de MQO e Within Groups Baltagi (2008).

Tais limitações são superadas por meio das estimações dos modelos dinâmicos com dados em painel, desenvolvidas a partir das estimações pelo Método dos Momentos Generalizados (GMM). Ademais, a utilização de modelos dinâmicos para dados em painel tem sua justificativa associada ao fato de que muitas séries econômicas se relacionam umas com as outras e com seus valores passados, o que, seguindo alguns estudos, parece ser o caso para entender a dinâmica do desmatamento.

O GMM oferece uma alternativa para tratar os efeitos individuais por meio do uso de variáveis instrumentais. E, distintamente das estimativas em painel estático (efeito fixo ou aleatório), em que ocorre viés nos coeficientes estimados quando se incluem variáveis dependentes defasadas como regressores, as variáveis instrumentais podem fornecer estimadores não viesados.

O estimador do GMM de Arellano \& Bond (1991), denominado de GMMDIF, instrumentaliza as variáveis explicativas em diferença que não são estritamente exógenas com suas defasagens disponíveis em nível. Contudo, nesse estimador GMM de primeira diferença, as defasagens em nível disponíveis podem ser instrumentos fracos para as variáveis não estritamente exógenas caso essas defasagens possam ser caracterizadas como um passeio aleatório.

Por outro lado, o método de estimação desenvolvido por Arellano \& Bover (1995) e Blundell \& Bond (1998), denominado de GMM-SYSTEM, mostrou-se mais adequado para amostras pequenas, especialmente, quando a dimensão temporal é curta e as variáveis independentes são fortemente correlacionadas, o que é aplicável ao caso em estudo. O objetivo da utilização do GMM neste trabalho é, então, o de encontrar um estimador consistente com um mínimo de restrições sobre os momentos.

A diferença do estimador GMM-SYSTEM em relação ao estimador GMMDIF é que este primeiro combina a instrumentalização das variáveis defasadas em nível com defasagens em diferenças, relacionando-as, ainda, com as condições iniciais dessas variáveis. Isso diminui o problema atribuído ao estimador GMM-DIF relacionado ao fato de que os níveis defasados das variáveis carregam poucas informações sobre suas mudanças futuras, o que torna fraco os instrumentos derivados em primeira diferença dessas variáveis Blundell \& Bond (1998). Mas, em compensação, eleva-se o número de instrumentos e pode funcionar em pequenas amostras. E isso confere melhores propriedades de amostra finita em termos de viés e erro quadrático. Além disso, o processo

\footnotetext{
${ }^{5} \mathrm{Ou}$ seja, $E\left(\right.$ txdesmat $\left._{i, t-1}, \varepsilon_{i t}\right) \neq 0$. Valendo a pena ressaltar que, uma variável pode ser rotulada como: estritamente exógena, quando não é correlacionada com o erro passado, presente e futuro; fracamente exógena, se é correlacionada apenas com o passado do erro; e endógena, quando é correlacionada com o erro passado, presente e futuro.
} 
que envolve a estimação em dois estágios apresenta como vantagem a utilização de erros-padrão mais eficientes.

Ademais, foram testadas duas variações da especificação original (GMMSYS), uma considerando a defasagem a um período das variáveis drivers do desmatamento e outra além dessas defasagens citadas, à introdução de duas variáveis dummies espaciais para os estados que mais contribuem para desmatamento, o Pará e o Mato Grosso, interadas com as atividades promotoras do desmatamento mais expressivas nesses estados, pecuária no Pará (efetbovapa) e cultura temporária no Mato Grosso (cultempmt). Assim, o modelo original será denominado GMM-SYS 1; o modelo com a segunda especificação de GMM-SYS 2, e o modelo com a terceira especificação de GMM-SYS 3.

Vale, por fim, observar que a disposição dos dados na forma de um painel dinâmico, como definido, permitirá também verificar duas outras hipóteses subjacentes à evolução do desmatamento no tempo, quais sejam, seu efeito defasado (persistência temporal), nesse caso, com base no modelo dinâmico GMM-SYSTEM, e, ainda, a possibilidade de se testar a regularidade empírica do chamado efeito: Curva de Kuznets Ambiental (CKA).

\subsection{Descrição dos Dados}

A base de dados é uma combinação basicamente de três fontes: a base de referência do Projeto de Monitoramento da Floresta Amazônica por Satélite (PRODES), do Instituto Nacional de Pesquisas Espaciais (INPE) para o desmatamento. As pesquisas da Produção Agrícola Municipal (PAM) e a Produção da Pecuária Municipal (PPM) do IBGE e os dados sobre renda, pobreza e indicadores de qualidade de vida, inclusive, IDHM coletados do Atlas do Desenvolvimento Humano do Programa das Nações Unidas para o Desenvolvimento (PNUD) $)^{6}$.

Todavia, muitas outras referências de dados primários e secundários foram utilizadas, como a base de dados dos assentamentos rurais disponibilizada pelo Sistema SIPRA dos Projetos de Reforma Agrária do Instituto Nacional de Colonização e Reforma Agrária (INCRA) e mesmo as tabulações realizadas e disponibilizadas pelo IPEADATA. A Tabela 2, como mencionada antes, apresenta a lista completa das variáveis utilizadas, bem como suas descrições, abreviações, fontes e os respectivos sinais esperados, seguindo a literatura.

Algumas observações acerca da utilização desses dados e variáveis definidas são importantes. Primeiro, as variáveis relacionadas ao número de famílias assentadas e área do assentamento foram acumuladas ano a ano. A variável considerada nesse caso foi o número de famílias destinadas aos assentamentos.

Por sua vez, para considerar a pobreza rural, admitiu-se um número médio de cinco indivíduos por família, multiplicando-se o número de famílias por cinco e o resultado dividiu-se pela população do município. O resultado foi tomado como uma medida proxy da proporção de pobres do município (ou pelo menos da população rural). A Tabela 3 resume as estatísticas descritivas das variáveis utilizadas.

Por fim, como os dados foram estimados em logaritmos, adotou-se o procedimento de considerar como zero logaritmo da variável dependente, proxy

\footnotetext{
${ }^{6}$ Tabulado em parceria com a Fundação Joaquim Pinheiro (FJP) e Instituto de Pesquisa Econômica Aplicada (IPEA).
} 
Tabela 2: Descrições e fontes de dados das variáveis

\begin{tabular}{c|l|c|c|c}
\hline Variáveis & \multicolumn{1}{c|}{ Descrições das Variáveis } & $\begin{array}{c}\text { Abreviatura } \\
\text { da Variável }\end{array}$ & Fontes & $\begin{array}{c}\text { Sinal } \\
\text { Esperado }\end{array}$ \\
\hline Desmatamento & Taxa de desmatamento do município & txdesm & INPE & + \\
\hline Assentamento & $\begin{array}{l}\text { Soma acumulada do número de famílias as- } \\
\text { sentadas no município }\end{array}$ & $\begin{array}{c}\text { INCRA/ } \\
\text { MDA }\end{array}$ & + \\
\hline Pobreza & $\begin{array}{l}\text { Variável fam como definida multiplicada pelo } \\
\text { número médio de indivíduos da família divi- } \\
\text { dida pela população do município }\end{array}$ & pnas & IBGE & $-/+$ \\
\hline $\begin{array}{c}\text { PIB } \\
\text { per capita }\end{array}$ & Produto Interno Bruto & pib & IPEA & $-/+$ \\
\hline Pecuária & $\begin{array}{l}\text { Efetivo bovino dividido pela área do municí- } \\
\text { pio }\end{array}$ & efetbova & IPEA & + \\
\hline $\begin{array}{c}\text { Cultura } \\
\text { Permanente }\end{array}$ & $\begin{array}{l}\text { Área plantada do município destinada a cul- } \\
\text { tura permanente }\end{array}$ & cultperm & IBGE & + \\
\hline $\begin{array}{c}\text { Cultura } \\
\text { Temporária }\end{array}$ & $\begin{array}{l}\text { Área plantada do município destinada a cul- } \\
\text { tura temporária }\end{array}$ & culttemp & IBGE & + \\
\hline $\begin{array}{c}\text { Densidade } \\
\text { Demográfica }\end{array}$ & $\begin{array}{l}\text { Relação entre a população e a área do municí- } \\
\text { pio }\end{array}$ & dens & IBGE & + \\
\hline $\begin{array}{c}\text { Distância } \\
\text { da Capital }\end{array}$ & Distância do município à capital & distcap & IBGE & - \\
\hline $\begin{array}{l}\text { Regulação } \\
\text { Ambiental }\end{array}$ & $\begin{array}{l}\text { Variável dummy construída com 1 para os } \\
\text { anos em que houve política regulatória e, 0 } \\
\text { caso contrário }\end{array}$ & reg & IBAMA & - \\
\hline
\end{tabular}


do desmatamento, em que essa variável era zero em nível. As variáveis explicativas (independentes) foram selecionadas com base na literatura empírica, em que pese as principais variáveis apontadas por essa literatura como determinantes do desmatamento ${ }^{7}$.

Tabela 3: Estatísticas descritivas

\begin{tabular}{c|r|c|r|r}
\hline Variáveis & Média & Desvio-padrão & Mínimo & Máximo \\
\hline txdesm & 6,1477 & 1,5457 & $-2,3026$ & 9,7412 \\
efetbova & 2,5482 & 1,8828 & $-7,4808$ & 5,8066 \\
culperm & 0,4737 & 1,7736 & $-4,6052$ & 5,6917 \\
culttemp & 3,4150 & 1,5868 & $-2,9957$ & 9,0453 \\
pib & 10,5838 & 1,1977 & 7,4813 & 16,8921 \\
dens & 1,6888 & 1,4645 & $-2,6086$ & 7,9130 \\
distcap & 5,3979 & 1,0382 & 0,0000 & 7,2973 \\
fam & 3,8835 & 1,1164 & $-9,6079$ & 0,2507 \\
pnas & $-2,0957$ & 1,3447 & $-7,9571$ & 1,2666 \\
\hline
\end{tabular}

Nota: Variáveis logaritimizadas. Fonte: Elaboração dos autores.

\section{Resultados e Discussões}

Para aferir o efeito das mudanças institucionais sobre o desmatamento ocorridas entre os anos de 2000 e 2010, bem como, testar outros efeitos da política pública, como da política de assentamentos para a Reforma Agrária ocorrida, também nesse período, considerando um painel de informações de municípios dos estados da Amazônia Legal, estima-se a Equação (1) pelos métodos MQO, Within Groups e GMM-SYSTEM ${ }^{8}$. Entretanto, dar-se-á, maior relevância às estimações via GMM-SYSTEM, pelo apreço à heterogeneidade individual dos munícipios da Amazônia Legal, os efeitos não observados poe meio de instrumentos internos e a correlação entre as variáveis explicativas, originando assim estimativas robustas que eliminam os problemas inerentes a endogeneidade.

Nesse sentido, divide-se esta seção em duas partes. Na Subseção 4.1, realizase a análise dos testes de especificação e, em seguida, na Subseção 4.2, interpretase os resultados.

\subsection{Testes de Especificação}

Uma das etapas do tratamento de dados em painel consiste na verificação da presença de raiz unitária, análoga ao estudo de séries temporais, uma vez que esta, em dados em painel, pode induzir a uma relação econométrica espúria. Por isso, antes da estimação dos modelos por MQO, Within Groups e GMMSYSTEM foram realizados testes de raiz unitária (Apêndice A).

\footnotetext{
${ }^{7}$ Uma variável que denote a atividade madeireira não foi considerada no modelo, uma vez que não existem informações relativamente confiáveis sobre a mesma. Uma proxy com base nos dados da RAIS/MTE poderia ter sido utilizada, mas como boa parte da atividade é não informal, entre 80 a $100 \%$, isso poderia criar algum tipo de viés indesejável comprometendo os resultados das estimativas.

${ }^{8}$ Assim como as variações da Equação (1).
} 
A Tabela 5 reporta os resultados dos testes de raiz unitária Levin et al. (2002), Breitung (2001), ADF-Fisher e o PP-Fisher Baltagi (2008) com intercepto individual e intercepto e tendências individuais. Como pode ser observado quando os efeitos fixos são controlados, com exceção da variável densidade demográfica, todas as demais variáveis, pela maioria dos testes, em ambos os casos, a 1\% de significância, pode-se rejeitar a hipótese nula de que as séries possuem raiz unitária. Portanto, as séries podem ser consideradas estacionárias em nível, ou seja, $I(0)$. Nesse contexto, como a variável densidade demográfica apresentou raiz unitária, diferenciou-se a mesma, $D$ (dens), e procedeu novamente com o teste de raiz unitária, os resultados dos testes revelam que, a mesma é estacionária em primeira diferença, ou seja, $I(1)$.

Os resultados dos testes de restrição de sobreidentificação, Teste de Sargan $\left(\chi^{2}(3)=3,39\right.$, com Prob $\left.>\chi^{2}=0,335\right)$ e Teste de Hansen $\left(\chi^{2}(3)=1,11\right.$, com Prob $\left.>\chi^{2}=0,775\right)$, do modelo GMM-SYS 1 asseguram a escolha dessa especificação ${ }^{9}$. Da mesma forma, em relação aos testes de autocorrelação de primeira e segunda ordem de Arellano \& Bond (1991), que confirmam a rejeição da autocorrelação de primeira ordem (Prob $>z=0,001)$, mas não se rejeita a autocorrelação de segunda ordem $(\operatorname{Prob}>z=0,732)$, denota-se que as estimativas são consistentes ${ }^{10}$.

Os resultados dos testes apresentados na Tabela 4 (GMM-SYS com suas variações), assim como o observado na Tabela 6 (MQO e Within Groups) presente no Apêndice $B$, sugerem a pertinência da utilização do modelo dinâmico (no caso GMM-SYS). Além disso, como se trata de um painel com dimensão temporal pequena, o modelo estimado foi realizado em dois estágios (two steps), que utiliza a chamada correção de Windmeijer (2005) para tornar as estimativas mais consistentes, ao mesmo tempo, que se procedeu à alternativa de colapsar os instrumentos ${ }^{11}$.

\subsection{Interpretação dos Resultados}

Um primeiro resultado diz respeito aos coeficientes da variável dependente defasada (desmatamento no ano anterior), que foram significantes e positivos em todas as especificações do modelo GMM-SYS, e apresentando elevada elasticidade confirmando a importância da persistência do desmatamento no tempo (Tabela 4).

Um outro resultado comum as especificações do modelo GMM-SYS, foram as estimativas significantes e com sinal negativo da variável dummy regulação (reg), que denota um efeito dinâmico inibidor das políticas de comando e controle do desmatamento, como apontado em estudos empíricos como de Assunção et al. (2015), Ferreira \& Coelho (2015).

Os resultados das estimativas dos modelos GMM-SYS foram, entretanto, diferentes quanto aos principais drivers do desmatamento. Assim, na especificação 1 (GMM-SYS 1) foi significante e com sinal positivo, apenas a variável

\footnotetext{
${ }^{9} \mathrm{Em}$ todos os modelos, as variáveis endógenas defasadas foram consideradas como predeterminadas, as demais variáveis explicativas foram tomadas como exógenas.

${ }^{10}$ As variações do modelo original (GMM-SYS 2 e 3), seguiram os mesmos procedimentos metodológicos desse primeiro modelo, e os resultados dos testes de especificação (Sargan, Hansen e de autocorrelação) apresentados na Tabela 4, atestam, também, a pertinência de sua utilização.

${ }^{11}$ Para uma discussão dos procedimentos utilizados que envolvem o processo de estimação, as diferenças entre os modelos GMM-DIF e GMM-SYS e a superação dos problemas relacionados à existência de muitos instrumentos ver, respectivamente, Roodman $(2009 a, b)$.
} 
Tabela 4: Resultado do modelo GMM-SYSTEM

\begin{tabular}{|c|c|c|c|c|c|}
\hline \multicolumn{2}{|c|}{ GMM-SYS 1} & \multicolumn{2}{|c|}{ GMM-SYS 2} & \multicolumn{2}{|c|}{ GMM-SYS 3} \\
\hline Varáveis & Coeficientes & Varáveis & Coeficientes & Varáveis & Coeficientes \\
\hline txdesm $_{i, t-1}$ & $\begin{array}{c}0,9487^{*} \\
(0,0247)\end{array}$ & $\operatorname{txdes}_{i, t-1}$ & $\begin{array}{c}1,0307^{*} \\
(0,0283)\end{array}$ & txdesm $m_{i, t-1}$ & $\begin{array}{c}1,0402^{*} \\
(0,0342)\end{array}$ \\
\hline reg & $\begin{array}{c}-0,0412^{*} \\
(0,0095)\end{array}$ & reg & $\begin{array}{r}-0,0483^{*} \\
(0,0089)\end{array}$ & reg & $\begin{array}{c}-0,0547^{*} \\
(0,0080)\end{array}$ \\
\hline efetbova & $\begin{array}{c}0,0041 \\
(0,0044)\end{array}$ & efetbova & $\begin{array}{c}-0,0832 \\
(0,0852)\end{array}$ & efetbova & $\begin{array}{c}-0,1581^{*} \\
(0,0621)\end{array}$ \\
\hline cultperm & $\begin{array}{c}0,0108^{* *} \\
(0,0048)\end{array}$ & efetbova $a_{i, t-1}$ & $\begin{array}{c}0,0725^{*} \\
(0,0883)\end{array}$ & ef etbova $a_{i, t-1}$ & $\begin{array}{c}0,1543^{* *} \\
(0,0650)\end{array}$ \\
\hline cultemp & $\begin{array}{c}0,0056 \\
(0,0061)\end{array}$ & cultperm & $\begin{array}{c}-0,0545^{* *} \\
(0,0247)\end{array}$ & efetbovapa & $\begin{array}{c}-0,0453^{* *} \\
(0,0208)\end{array}$ \\
\hline pib & $\begin{array}{c}0,0837 \\
(0,0671)\end{array}$ & cultperm $_{i, t-1}$ & $\begin{array}{c}0,0559^{*} \\
(0,0257)\end{array}$ & cultperm & $\begin{array}{r}-0,0626^{*} \\
(0,0250)\end{array}$ \\
\hline$p i b_{i, t-1}$ & $\begin{array}{c}0,1063^{* *} \\
(0,0537)\end{array}$ & cultemp & $\begin{array}{c}-0,0812^{*} \\
(0,0401)\end{array}$ & cultperm $_{i, t-1}$ & $\begin{array}{c}0,0683^{*} \\
(0,0256)\end{array}$ \\
\hline$p i b_{i, t-2}$ & $\begin{array}{c}0,0052 \\
(0,0108)\end{array}$ & cultemp $_{i, t-1}$ & $\begin{array}{c}0,0785^{* *} \\
(0,0423)\end{array}$ & cultemp & $\begin{array}{c}-0,0843^{* *} \\
(0,0378)\end{array}$ \\
\hline fam & $\begin{array}{c}-0,0070 \\
(0,0306)\end{array}$ & pib & $\begin{array}{c}0,0654^{* *} \\
(0,0294)\end{array}$ & cultemp $_{i, t-1}$ & $\begin{array}{c}0,0738^{* *} \\
(0,0355)\end{array}$ \\
\hline pnas & $\begin{array}{c}0,0237 \\
(0,0333)\end{array}$ & $p i b_{i, t-1}$ & $\begin{array}{c}-0,0663^{* *} \\
(0,0347)\end{array}$ & cultempmt & $\begin{array}{c}0,0024^{*} \\
(0,0115)\end{array}$ \\
\hline distcap & $\begin{array}{c}-0,0127 \\
(0,0230)\end{array}$ & $p i b_{i, t-2}$ & $\begin{array}{c}0,0031 \\
(0,0122)\end{array}$ & pib & $\begin{array}{r}0,0602^{*} \\
(0,0234)\end{array}$ \\
\hline dens & $\begin{array}{c}0,0181 \\
(0,0187)\end{array}$ & fam & $\begin{array}{c}-0,0152 \\
(0,0134)\end{array}$ & $p i b_{i, t-1}$ & $\begin{array}{c}-0,0791^{*} \\
(0,0275)\end{array}$ \\
\hline const & $\begin{array}{c}0,1998 \\
(0,1410)\end{array}$ & pnas & $\begin{array}{c}0,0102 \\
(0,0084)\end{array}$ & $p i b_{i, t-2}$ & $\begin{array}{c}0,0111 \\
(0,0128)\end{array}$ \\
\hline & & distcap & $\begin{array}{c}0,0186^{*} \\
(0,0119)\end{array}$ & fam & $\begin{array}{c}0,0118 \\
(0,0211)\end{array}$ \\
\hline & & dens & $\begin{array}{c}0,0106 \\
(0,0097)\end{array}$ & pnas & $\begin{array}{c}-0,0140 \\
(0,0194)\end{array}$ \\
\hline & & const & $\begin{array}{c}-0,1140 \\
(0,1290)\end{array}$ & distcap & $\begin{array}{c}0,0428^{* *} \\
(0,0192)\end{array}$ \\
\hline & & & & dens & $\begin{array}{c}0,0065 \\
(0,0142)\end{array}$ \\
\hline & & & & const & $\begin{array}{c}0,3766^{* * * *} \\
(0,2136) \\
\end{array}$ \\
\hline $\mathrm{N}$ & 4323 & $\mathrm{~N}$ & 4323 & $\mathrm{~N}$ & 4323 \\
\hline Grupos & 517 & Grupc & 517 & Grupos & 517 \\
\hline Instrumentos & 23 & Instrumentos & 23 & Instrumentos & 23 \\
\hline Teste de Sargan & {$[0,3330]$} & Teste de Sargan & {$[0,2920]$} & Teste de Sargan & {$[0,5360]$} \\
\hline Teste de Hansen & {$[0,7750]$} & Teste de Hansen & $\mathrm{n} \quad[0,3110]$ & Teste de Hansen & $\mathrm{n}[0,6360]$ \\
\hline Teste AR(1) & {$[0,0010]$} & Teste AR(1) & {$[0,0090]$} & Teste AR(1) & {$[0,0001]$} \\
\hline Teste AR(2) & {$[0,7320]$} & Teste AR(2) & {$[0,3650]$} & Teste AR(2) & {$[0,2690]$} \\
\hline
\end{tabular}

Fonte: Elaboração dos autores com aplicação do programa Stata 13.0.

Nota: $\left({ }^{*}\right)$ significante a $1 \% ;\left({ }^{* *}\right)$ significante a $5 \% ;\left(^{* * *}\right)$ significante a $10 \%$. Foram estimadas variáveis dummies de tempo, omitidas na tabela, mas que foram todas significantes. Ademais as variáveis foram estimadas em logaritmo natural. 
relacionada ao crescimento da cultura permanente (cultperm), não sendo significantes as proxies para a evolução da atividade pecuária (efetbova), bem como, para a expansão da cultura temporária (cultemp). Na especificação GMM-SYS 2, a variável relacionada a evolução da pecuária (efetbova), foi não significante, bem como, de sua defasagem a um período $\left(e f\right.$ etbova $\left.a_{i, t-1}\right)$. Todavia, foram significantes as variáveis que denotam a expansão das culturas permanentes (cultperm), e temporárias (cultemp), ambas com sinal negativo, em seu efeito contemporâneo, bem como em relação às suas respectivas defasagens a um período, cultperm $m_{i, t-1}$ e cultemp $p_{i, t-1}$, ambas com sinal positivo. Na especificação GMM-SYS 3, esses mesmos resultados são replicados, e, ainda, em relação às variáveis proxies da pecuária, em seu efeito contemporâneo (efetbova) positivo e defasado (efetbova $a_{i, t-1}$ ), negativo, que passam agora a serem significantes.

Os resultados (modelo GMM-SYS 3) podem significar que o crescimento no ano anterior das atividades drivers do desmatamento, pecuária e cultura permanente e temporária leva à intensificação do desmatamento no ano corrente, embora o efeito contemporâneo dessas variáveis seja negativo, reforçado, ainda, pelo efeito espacial para os estados do Pará e Mato Grosso. Tal processo, pode indicar que o crescimento das atividades mencionadas ocorra em um primeiro momento a partir da apropriação de terra nova e em um segundo momento pela elevação da densidade daquela forma de ocupação (hectares por $\mathrm{km}^{2}$ com pasto ou lavoura), uma característica observada entre os dados censitários de 1995 e 2006 (IPEA 2013). Ademais, no caso específico da pecuária, essa dinâmica pode ser representativa da elevação da taxa de lotação dos animais nos imóveis rurais, com menor impacto sobre novas áreas de floresta nativa.

Com relação à variável PIB, defasada em dois períodos, os resultados evidenciaram significância estatísticas e com sinal positivo apenas para o primeiro lag, quanto ao modelo GMM-SYS 1, mas para as especificações GMMSYS 2 e GMM-SYS 3, a variável defasada a dois períodos não foi significante, não obstante para sua defasagem a um período e efeito contemporâneo foram significantes e com sinal negativo e positivo, respectivamente. Assim, esses resultados parecem refutar a evidência de uma CKA para a relação entre PIB e desmatamento no contexto dos municípios da Amazônia Legal, entre os anos de 2000 a 2010.

Observa-se, ainda, que variável distância do município à capital (distcap) não foi significante no primeiro modelo GMM-SYS 1, enquanto que para as especificações GMM-SYS 2 e GMM-SYS 3 foram significantes e com sinal positivo, como inicialmente esperado, corroborando a hipótese de que quanto mais distante o município da capital, menor sua disponibilidade de acesso a infraestrutura urbana, bem como do aparato institucional, que regula as atividades promotoras do desmatamento.

Por seu turno, as variáveis proxies da pobreza (fam) e (pnas) não foram estatisticamente significantes em todas as especificações do modelo dinâmico, sendo que no modelo GMM-SYS 3, os sinais das estimativas são, respectivamente, positivo e negativo. O que pode ser atribuído à baixa capacidade (escala de intervenção) como agente promotor do desmatamento dos agentes pobres, especialmente quando comparado aos agentes mais capitalizados e que dispõe de tecnologia de maior impacto na derrubada da floresta. 


\section{Considerações Finais}

Ao encontro de verificar empiricamente os efeitos de diferentes fatores que constituiriam os determinantes primários e subjacentes do desmatamento na Amazônia Legal brasileira, esse modelo, para uma estrutura de dados em forma de painel dinâmico, aplicado no período entre os anos de 2000 e 2010, corroborou a expectativa da determinação das variáveis explicativas selecionadas sobre o desmatamento ao encontro da literatura empírica referenciada neste estudo.

Por meio dos resultados do modelo GMM-SYS, evidenciou-se a importância da persistência do desmatamento no tempo, com a variável dependente defasada a um período, significante e positiva e com elevada elasticidade em todas as variações definidas.

Outro resultado comum foi observado nas três especificações do modelo GMM-SYS, quanto ao resultado significante da variável regulação (reg) com sinal negativo, denotando que o efeito dinâmico da política de comando e controle tem alcançado seu objetivo de restrição ao desmatamento, como esperado e indicado por outros estudos empíricos, em particular, Assunção et al. (2015), Ferreira \& Coelho (2015).

Quanto as variáveis drivers do desmatamento, na especificação com essas variáveis defasadas a um período e dummy espacial interada com a pecuária (efetbova) para o Pará e com a cultura temporária (cultemp) para o Mato Grosso, modelo GMM-SYS 3, verificou-se sua significância estatística e com sinais negativos para a variável defasada e positivo para a variável contemporânea, processo este que pode indicar que o crescimento das atividades mencionadas ocorra em um primeiro momento a partir da apropriação de terra nova e em um segundo momento pela elevação da densidade daquela forma de ocupação (hectares por $\mathrm{km}^{2}$ com pasto ou lavoura), uma característica observada entre os dados censitários de 1995 e 2006 (IPEA, 2013). Ademais, no caso específico da pecuária, essa dinâmica pode ser representativa da elevação da taxa de lotação dos animais nos imóveis rurais, com menor impacto sobre novas áreas de floresta nativa.

Com relação à variável PIB, defasada em dois períodos, observou-se nos modelos GMM-SYS 2 e GMM-SYS 3 que o efeito contemporâneo é positivo, enquanto o efeito defasado a um período é negativo, refutando, em princípio, a evidência de uma CKA para a relação entre PIB e desmatamento no contexto dos municípios da Amazônia Legal, entre os anos de 2000 a 2010.

Por fim, as variáveis proxies da proporção de pobres (pnas) e famílias assentadas $(\mathrm{fam})$ não foram significantes para explicar dinamicamente o desmatamento. Tais evidências não sustentam a hipótese de uma relação direta entre a política de assentamento e o desmatamento e, em princípio, esse resultado pode ser explicado considerando a baixa capacidade de intervenção desses agentes pobres sobre o uso e ocupação da terra e, portanto, de promover uma escala relevante sobre o desmatamento.

\section{Agradecimentos}

Os autores agradecem o apoio institucional (inclusive financeiro) do Conselho Nacional de Desenvolvimento Científico e Tecnológico (CNPQ). 


\section{Referências Bibliográficas}

Alencar, A., Pereira, C., Castro, I., Cardoso, A., Souza, L., Costa, R., Bentes, A. J., Stella, O., Azevedo, A., Gomes, J. et al. (2015), 'Desmatamento nos assentamentos da Amazônia: histórico, tendências e oportunidades', IPAM, Brasília, DF .

Alves, E. R. A. \& Rocha, D. P. (2010), 'Ganhar tempo é possível?'.

Andersen, L. E., Granger, C. W., Reis, E. J., Weinhold, D., Wunder, S. et al. (2002), The dynamics of deforestation and economic growth in the Brazilian Amazon, Cambridge University Press.

Arellano, M. \& Bond, S. (1991), 'Some tests of specification for panel data: Monte Carlo evidence and an application to employment equations', The Review of Economic Studies 58(2), 277-297.

Arellano, M. \& Bover, O. (1995), 'Another look at the instrumental variable estimation of error-components models', Journal of Econometrics 68(1), 2951 .

Arima, E. (2001), 'Desmatamento e economia local e políticas públicas', Causas e Dinâmicas do Desmatamento da Amazônia pp. 259-275.

Arima, E., Barreto, P. \& Brito, M. (2005), Pecuária na Amazônia: tendências e implicações para a conservação ambiental, number 636.08098113 A699.

Arima, E. Y. \& Uhl, C. (1997), 'Ranching in the Brazilian Amazon in a national context: economics, policy, and practice', Society $\mathcal{E}$ Natural Resources 10(5), 433-451.

Assunção, J., Gandour, C. \& Rocha, R. (2015), 'Deforestation slowdown in the Brazilian Amazon: prices or policies?', Environment and Development Economics 20(6), 697-722.

Bai, J. \& Ng, S. (2001), 'A panic attack on unit roots and cointegration, Boston College, Department of Economics', Unpublished Manuscript .

Baltagi, B. (2008), Econometric Analysis of Panel Data, John Wiley \& Sons.

Banerjee, A. (1999), 'Panel data unit roots and cointegration: an overview', Oxford Bulletin of Economics and Statistics 61(S1), 607-629.

Barreto, P. (2008), A pecuária e o desmatamento na Amazônia na era das mudanças climáticas, IMAZON.

Barreto, P., Souza Jr, C., Noguerón, R., Anderson, A. \& Salomão, R. (2005), 'Pressão humana na floresta amazônica brasileira', Belém, World Resource Institute.

Blundell, R. \& Bond, S. (1998), 'Initial conditions and moment restrictions in dynamic panel data models', Journal of Econometrics 87(1), 115-143.

Brandão Jr, A. \& Souza Jr, C. (2006), 'Mapping unofficial roads with Landsat images: a new tool to improve the monitoring of the Brazilian Amazon rainforest', International Journal of Remote Sensing 27(1), 177-189. 
Breitung, J. (2001), The local power of some unit root tests for panel data, in 'Nonstationary panels, panel cointegration, and dynamic panels', Emerald Group Publishing Limited, pp. 161-177.

Buainain, A. M. \& Garcia, J. R. (2013), 'Os pequenos produtores rurais mais pobres ainda tem alguma chance como agricultores', Centro de Gestão e Estudos Estratégicos-CGEE, A pequena produção rural e as tendências do desenvolvimento agrário brasileiro: ganhar tempo é possivel pp. 29-72.

Castro, E. (2005), 'Dinâmica socioeconômica e desmatamento na Amazônia', Novos Cadernos NAEA 8(2).

Choi, I. (2001), 'Unit root tests for panel data', Journal of International Money and Finance 20(2), 249-272.

Chomitz, K., Buys, P., Luca, G., Thomas, T. \& Wertz-Kanounnikoff, S. (2007), 'At loggerheads: agricultural expansion', Poverty Reduction, and Environment in the Tropical Forests .

Côrtes, J. C. \& Oliveira, Á. D. (2014), 'Dinâmicas no uso e cobertura da terra: perspectivas e desafios da demografia', Revista Brasileira de Estudos de População 31(1), 191-210.

Diaz-Balteiro, L., Casimiro Herruzo, A., Martinez, M. \& Gonzalez-Pachon, J. (2006), 'An analysis of productive efficiency and innovation activity using DEA: an application to Spain's wood-based industry', Forest Policy and Economics 8(7), 762-773.

Diniz, M. B., Oliveira Junior, J. N., Trompieri Neto, N. \& Diniz, M. J. T. (2009), 'Causas do desmatamento da Amazônia: uma aplicação do teste de causalidade de Granger acerca das principais fontes de desmatamento nos municípios da Amazônia Legal brasileira', Nova Economia 19(1), 121-151.

Domingues, M. S. \& Bermann, C. (2012), 'O arco de desflorestamento na amazônia: da pecuária à soja', Ambiente e sociedade 15(2), 1-22.

Fearnside, P. M. (2006), 'Desmatamento na Amazônia: dinâmica, impactos e controle'.

Ferreira, M. D. P. \& Coelho, A. B. (2015), 'Desmatamento recente nos estados da Amazônia Legal: uma análise da contribuição dos preços agrícolas e das políticas governamentais', Revista de Economia e Sociologia Rural 53(1), 91108.

Finco, M. V. A. et al. (2009), 'Poverty-environment trap: a non linear probit model applied to rural areas in the North of Brazil', American-Eurasian Journal of Agricultural and Environmental Science 5(4), 533-539.

Gasques, J. G., Vieira Filho, J. E. R. \& Navarro, Z. (2010), A agricultura brasileira: desempenho, desafios e perspectivas., Brasília, DF: IPEA, 2010.

Gazoni, J. L. \& Mota, J. A. (2010), 'Fatores político-econômicos do desmatamento na Amazônia Oriental', Sustentabilidade em Debate 1(1), 25-42.

Geist, H. J. \& Lambin, E. F. (2001), 'What drives tropical deforestation', LUCC Report Series 4, 116. 
Gomes, S. C., Braga, M. J. et al. (2008), Desenvolvimento econômico e desmatamento na Amazônia Legal: uma análise econométrica, in '46th Congress, July 20-23, 2008, Rio Branco, Acre, Brasil', number 103095, Sociedade Brasileira de Economia, Administração e Sociologia Rural (SOBER).

Grossman, G. M. \& Krueger, A. B. (1995), 'Economic growth and the environment', The Quarterly Journal of Economics 110(2), 353-377.

Hecht, S. B. (1985), 'Environment, development and politics: capital accumulation and the livestock sector in eastern Amazonia', World Development 13(6), 663-684.

Hecht, S. B. (2012), The natures of progress: land use dynamics and forest trends in Latin America and the Caribbean, Technical report, Inter-American Development Bank.

Helfand, S. M. \& Pereira, V. F. (2012), 'Determinantes da pobreza rural e implicações para as políticas públicas no Brasil', A Nova Cara da Pobreza Rural: Desafios para as Politicas Públicas 16.

Hurlin, C. \& Mignon, V. (2007), 'Second generation panel unit root tests'.

Im, K. S., Pesaran, M. H. \& Shin, Y. (2003), 'Testing for unit roots in heterogeneous panels', Journal of Econometrics 115(1), 53-74.

Initiative, C. P., Assunção, J., e Gandour, C. C. \& Rocha, R. (n.d.), 'Deforestation slowdown in the Legal Amazon: prices or policies?'.

Kaimowitz, D. \& Angelsen, A. (1998), Economic models of tropical deforestation: a review, CIFOR.

Lambin, E. F. (1994), 'Modelling deforestation processes'.

Le Tourneau, F.-M. \& BurszTyn, M. (2010), 'Assentamentos rurais na Amazônia: contradições entre a política agrária e a política ambiental', Ambiente e Sociedade 13(1), 111-130.

Levin, A. \& Lin, C.-F. (1992), 'Unit root tests in panel data: asymptotic and finite-sample properties, University of California', San Diego, Mimeographed

Levin, A. \& Lin, C.-F. (1993), 'Unit root tests in panel data: new results', University of California at San Diego, Economics Working Paper Series .

Levin, A., Lin, C.-F. \& Chu, C.-S. J. (2002), 'Unit root tests in panel data: asymptotic and finite-sample properties', Journal of Econometrics 108(1), 124.

Maddala, G. S. \& Wu, S. (1999), 'A comparative study of unit root tests with panel data and a new simple test', Oxford Bulletin of Economics and Statistics 61(S1), 631-652.

Mahar, D. J. (1979), Frontier development policy in Brazil: a study of Amazônia, Praeger.

Mahar, D. J. et al. (1989), Government policies and deforestation in Brazil's Amazon region, World Bank. 
Margulis, S. (2003), 'Causas do desmatamento da Amazônia brasileira'.

Markandya, A. (2001), Poverty alleviation and sustainable development: implications for the management of natural capital, International Institute for Sustainable Development.

Moon, H. R. \& Perron, B. (2004), 'Testing for a unit root in panels with dynamic factors', Journal of Econometrics 122(1), 81-126.

Mueller, C. C. (1992), 'Dinâmica, condicionantes e impactos socioambientais da evolução da fronteira agrícola no Brasil', Revista de Administração Pública 26(3), 64-87.

Mueller, C. C. \& Bustamante, M. (2002), 'Análise da expansão da soja no Brazil, Analysis of the expansion of soybeans in Brazil', http://www. worldbank. org/rfpp/news/debates/mueller. pdf.

Nepstad, D., Carvalho, G., Barros, A. C., Alencar, A., Capobianco, J. P., Bishop, J., Moutinho, P., Lefebvre, P., Silva Jr, U. L. \& Prins, E. (2001), 'Road paving, fire regime feedbacks, and the future of Amazon forests', Forest Ecology and Management 154(3), 395-407.

Nepstad, D., Stickler, C. \& Almeida, O. (2008), 'A globalização das indústrias de soja e gado na Amazônia: oportunidade para conservação', Rivero, S. e Jayme Jr., FG, As Amazônias do Século XXI, Belém, Ed. da UFPa pp. 41-67.

Oliveira, R. C., Almeida, E., Freguglia, R. S. \& Barreto, R. C. S. (2011), 'Desmatamento e crescimento econômico no Brasil: uma análise da curva de Kuznets ambiental para a Amazônia Legal', Revista de Economia e Sociologia Rural 49(3), 709-739.

Panayotou, T. (2016), 'Economic growth and the environment', The environment in anthropology p. 140-148.

Pearce, D. W. \& Barbier, E. (2000), Blueprint for a sustainable economy, Earthscan.

Perz, S. G., Caldas, M. M., Arima, E. \& Walker, R. J. (2007), 'Unofficial road building in the Amazon: socioeconomic and biophysical explanations', Development and Change 38(3), 529-551.

Pesaran, M. H. (2007), 'A simple panel unit root test in the presence of crosssection dependence', Journal of Applied Econometrics 22(2), 265-312.

Pfaff, A., Kerr, S., Cavatassi, R., Davis, B., Lipper, L., Sanchez, A. \& Timmins, J. (2008), 'Effects of poverty on deforestation: distinguishing behaviour from location', Frontis pp. 101-115.

Pfaff, A. S. P. (1999), 'What drives deforestation in the Brazilian Amazon? Evidence from satellite and socioeconomic data', Journal of Environmental Economics and Management 37(1), 26-43.

Phillips, P. C. \& Sul, D. (2003), 'Dynamic panel estimation and homogeneity testing under cross-section dependence', The Econometrics Journal 6(1), 217259. 
Quah, D. (1994), 'Exploiting cross-section variation for unit root inference in dynamic data', Economics Letters 44(1-2), 9-19.

Reis, E. J. \& Guzmán, R. M. (1990), 'An econometric model of Amazon deforestation'.

Reis, E. J. \& Margulis, S. (1991), 'Perspectivas econômicas do desflorestamento da Amazônia'.

Roodman, D. (2009a), 'A note on the theme of too many instruments', Oxford Bulletin of Economics and Statistics 71(1), 135-158.

Roodman, D. (2009b), 'How to do xtabond2: an introduction to difference and system GMM in Stata', The Stata Journal 9(1), 86-136.

Sachs, J. D. \& Warner, A. M. (1995), Natural resource abundance and economic growth, Technical report, National Bureau of Economic Research.

Sachs, J. D. \& Warner, A. M. (2001), 'The curse of natural resources', European Eeconomic Review 45(4-6), 827-838.

Santos, A. M. A., Jacinto, P. A. \& Tejada, C. A. O. (2012), 'Causalidade entre renda e saúde: uma análise através da abordagem de dados em painel com os estados do Brasil', Estudos Econômicos (São Paulo) 42(2), 229-261.

Santos, R. B. N., Diniz, M. B., Diniz, M. J. T., Rivero, S. L. M., Oliveira Junior, J. N. et al. (2008), Estimativa da Curva de Kuznets Ambiental para a Amazônia Legal, in '46th Congress, July 20-23, 2008, Rio Branco, Acre, Brasil', number 113968, Sociedade Brasileira de Economia, Administração e Sociologia Rural (SOBER).

Scrieciu, S. (2007), 'Can economic causes of tropical deforestation be identified at a global level?', Ecological Economics 62(3-4), 603-612.

Stern, D. I. (2004), 'The rise and fall of the environmental Kuznets curve', World Development 32(8), 1419-1439.

Walker, R., Moran, E. \& Anselin, L. (2000), 'Deforestation and cattle ranching in the Brazilian Amazon: external capital and household processes', World Development 28(4), 683-699.

Weinhold, D. \& Reis, E. J. (2001), 'Model evaluation and causality testing in short panels: the case of infrastructure provision and population growth in the Brazilian Amazon', Journal of Regional Science 41(4), 639-657.

Windmeijer, F. (2005), 'A finite sample correction for the variance of linear efficient two-step GMM estimators', Journal of Econometrics 126(1), 25-51.

Wooldridge, J. M. (2010), Econometric analysis of cross-section and panel data, MIT Press.

Wunder, S. (2001), 'Poverty alleviation and tropical forests-what scope for synergies?', World Development 29(11), 1817-1833. 


\section{Apêndice A}

O estudo de raiz unitária em painel desempenhou um papel formidável na análise empírica a partir dos trabalhos seminais de Levin \& Lin (1992, 1993), Quah (1994). Esses testes foram introduzidos objetivando melhorar o poder estatístico dos testes de raiz unitária convencionais (baseados em séries temporais individuais), combinando informações da dimensão cross-section com o tamanho da série temporal Banerjee (1999). Os testes comumente usados para testar raiz unitária, como Dickey-Fuller, Augmented Dickey-Fuller e PhillipsPerron, falham em distinguir entre a hipótese nula de raiz unitária e alternativa de estacionariedade Maddala \& Wu (1999).

Nesse sentido, adicionar a dimensão cross-sectional à dimensão de tempo usual é muito importante no contexto de séries não estacionárias. Na verdade, é bem sabido que os testes de raiz unitária geralmente têm pouca potência em pequenos tamanhos de amostra para distinguir séries estacionárias persistentes e raiz unitária. Assim, aumentar o número de observações, incluindo informações relacionadas a várias unidades (indivíduos, países, estados, municípios, etc.), permite resolver o problema de baixa potência dos testes de raiz unitária em pequenas amostras Hurlin \& Mignon (2007), Baltagi (2008), Maddala \& Wu (1999).

A primeira diferença entre os testes de raiz unitária em dados de séries temporais e painel refere-se à heterogeneidade. No primeiro caso, a heterogeneidade não é um problema, uma vez que a hipótese de raiz unitária é testada em uma determinada unidade. As coisas são diferentes no segundo caso, e a literatura de dados em painel evoluiu em duas direções, testes de raiz unitária que consideram que as unidades são caracterizadas por dinâmicas iguais (diferentes) o painel é homogêneo (heterogêneo) ${ }^{12}$. Além disso, uma segunda evolução recente diz respeito à existência de dependências transversais. De acordo com os testes que (não) permitem correlações potenciais entre os resíduos das unidades do painel e, podem ser distinguidos em duas gerações de testes Hurlin \& Mignon (2007).

A primeira geração dos testes de raiz unitária de painel baseia-se na hipótese de independência cross-section e foram aplicados ao tratamento de micropaineis (um grande $\mathrm{N}$ e um pequeno $T$ ), podendo ser dividida em dois grupos. No primeiro grupo inclui os testes de Levin et al. (2002), Breitung (2001). Esses testes são considerados como sendo um teste de Dickey-Fuller Aumentado (ADF) com dados agrupados. A hipótese nula é a de que cada série do painel seja integrada de ordem um, contra a hipótese em que todas as séries sejam estacionárias. Os mesmos assumem a existência de um processo de raiz unitária comum, tal que os parâmetros para persistência para cada unidade (ou grupo) possuem a mesma estrutura autoregressiva, $\mathrm{AR}(1)$, além de permitir a existência do efeito individual Hurlin \& Mignon (2007), Baltagi (2008), Santos et al. (2012).

O segundo grupo congrega os testes Im; Im et al. (2003), ADF-Fisher e o PP-Fisher, os mesmos admitem a existência de um processo individual de raiz unitária de forma que os parâmetros de persistência podem variar livremente para cada unidade (grupo), nesse sentido, os testes são construídos a partir de estatísticas individuais. Esses testes adquirem a estrutura do ADF ao permitir que defasagens para a variável dependente possam ser inseridas, o que

${ }^{12}$ Baseado em um estimador agrupado do parâmetro autoregressivo. 
possibilita a autocorrelação do erro para cada série. A estatística do teste proposto por Im, Im et al. (2003), por exemplo, é o resultado de um média das $t$-estatísticas de Dickey-Fuller sobre cada unidade do painel, em que a hipótese nula é que, todas as séries são não estacionárias, ao passo que, na hipótese alternativa pelo menos uma série é estacionária. Já os testes ADF-Fisher e o PP-Fisher não levam em conta as $t$-estatísticas, mas derivam das combinações dos valores $p$ de cada teste de raiz unitária individual Hurlin \& Mignon (2007), Baltagi (2008), Santos et al. (2012).

Entretanto, a hipótese de independência é bastante restritiva e pouco realista na maioria das aplicações macroeconômicas ( $N$ e $T$ grandes) de teste de raiz unitária ${ }^{13}$. Em resposta à necessidade de testes de raiz unitária que permitam correlações transversais, vários testes foram propostos pertencentes aos que chamamos de teste de raiz unitária de segunda geração, também dividida em dois grupos. O primeiro deles baseia-se na abordagem de estrutura fatorial e incluem as contribuições de Bai \& Ng (2001), Phillips \& Sul (2003), Moon \& Perron (2004), Choi (2001) e Pesaran (2007). A segunda abordagem consiste em impor pouca ou nenhuma restrição na matriz de covariância residual, adotada por Chang (2002) Hurlin \& Mignon (2007), Baltagi (2008).

Diante do exposto, no presente artigo utiliza-se dos testes de raiz unitária de primeira geração, tendo em vista que, os mesmos são os mais apropriados para a estrutura de micropainel ( $N$ grande e $T$ pequeno), enquadramento dessa aplicação. Os testes realizados e a respectiva conclusão de seus resultados encontram-se na Tabela 5.

\section{Apêndice B}

Os resultados da estimativa da variável dependente defasada dos modelos MQO e Within Groups, respectivamente: 0,9978 e 0,7235, confirmam que o modelo GMM- System eliminou o viés da variável dependente defasada, uma vez que a estimativa obtida dessa variável nesse último modelo, 0,9487 (Tabela 6) encontra-se dentro dos limites das estimativas MQO e Within Groups.

\footnotetext{
${ }^{13} \mathrm{~A}$ aplicação de testes pertencentes à primeira geração em séries macroeconômicos que são caracterizadas por dependências transversais leva a distorções de tamanho e baixa potência Hurlin \& Mignon (2007).
} 
Tabela 5: Testes de raiz unitária

\begin{tabular}{|c|c|c|c|c|c|c|}
\hline Variáveis & $\begin{array}{l}\text { Levin, Lin } \\
\& \text { Chu } \mathbf{t}^{(2)}\end{array}$ & $\begin{array}{l}\text { Breitung } \\
t \text {-stat }\end{array}$ & $\begin{array}{c}\text { Im, Pesaran, } \\
\text { Shin } W \text {-stat } \\
(3)\end{array}$ & $\begin{array}{l}\text { ADF-Fisher } \\
\text { Chi-square }^{(3)}\end{array}$ & $\begin{array}{c}\text { PP-Fisher } \\
\text { Chi-square }^{(3)}\end{array}$ & Conclusão $^{(4)}$ \\
\hline \multicolumn{7}{|c|}{ Com Intercepto Individual ${ }^{(1)}$} \\
\hline txdesm & $\begin{array}{r}-180,0000^{*} \\
(0,0000)\end{array}$ & $\begin{array}{l}32,1362 \\
(1,0000)\end{array}$ & $\begin{array}{r}-120,0000^{*} \\
(0,0000)\end{array}$ & $\begin{array}{r}332,0111^{*} \\
(0,0000)\end{array}$ & $\begin{array}{r}726,4230^{*} \\
(0,0000)\end{array}$ & $I(0)$ \\
\hline efetbova & $\begin{array}{r}-46,0242^{*} \\
(0,0000)\end{array}$ & $\begin{array}{r}-3,5420^{*} \\
(0,0002)\end{array}$ & $\begin{array}{r}-12,9295^{*} \\
(0,0000)\end{array}$ & $\begin{array}{l}27,5350^{*} \\
(0,0000)\end{array}$ & $\begin{array}{l}37,3803^{*} \\
(0,0000)\end{array}$ & $I(0)$ \\
\hline cultperm & $\begin{array}{r}-36,5427^{*} \\
(0,0000)\end{array}$ & $\begin{array}{c}1,4652 \\
(0,9286)\end{array}$ & $\begin{array}{r}-1,8993^{*} \\
(0,0000)\end{array}$ & $\begin{array}{l}20,7195^{*} \\
(0,0000)\end{array}$ & $\begin{array}{l}17,1478^{*} \\
(0,0000)\end{array}$ & $I(0)$ \\
\hline culttemp & $\begin{array}{r}-43,3706^{*} \\
(0,0000)\end{array}$ & $\begin{array}{r}-5,0591^{*} \\
(0,0000)\end{array}$ & $\begin{array}{r}-8,4733^{*} \\
(0,0000)\end{array}$ & $\begin{array}{l}19,6951^{*} \\
(0,0000)\end{array}$ & $\begin{array}{l}19,5672^{*} \\
(0,0000)\end{array}$ & $I(0)$ \\
\hline pib & $\begin{array}{r}-30,8560^{*} \\
(0,0000)\end{array}$ & $\begin{array}{r}-5,6797^{*} \\
(0,0000)\end{array}$ & $\begin{array}{r}-10,8414^{*} \\
(0,0000)\end{array}$ & $\begin{array}{l}24,7142^{*} \\
(0,0000)\end{array}$ & $\begin{array}{l}18,9954^{*} \\
(0,0000)\end{array}$ & $I(0)$ \\
\hline dens & $\begin{array}{c}4,8023 \\
(1,0000)\end{array}$ & $\begin{array}{c}-0,0347 \\
(0,4862)\end{array}$ & $\begin{array}{l}12,9815 \\
(1,0000)\end{array}$ & $\begin{array}{r}-11,1946 \\
(1,0000)\end{array}$ & $\begin{array}{c}-6,8358 \\
(1,0000)\end{array}$ & $I(1)$ \\
\hline$D$ (dens) & $\begin{array}{r}-9,9204^{*} \\
(0,0000)\end{array}$ & $\begin{array}{r}-14,8304^{*} \\
(0,0000)\end{array}$ & $\begin{array}{r}-9,9929^{*} \\
(0,0000)\end{array}$ & $\begin{array}{l}22,8803^{*} \\
(0,0000)\end{array}$ & $\begin{array}{l}86,6537 \\
(0,0000)\end{array}$ & $I(1)$ \\
\hline fam & $\begin{array}{r}-36,0739^{*} \\
(0,0000)\end{array}$ & $\begin{array}{c}-6,8711^{*} \\
(0,0000)\end{array}$ & $\begin{array}{c}0,2465 \\
(0,5974)\end{array}$ & $\begin{array}{r}4,4278^{*} \\
(0,0000)\end{array}$ & $\begin{array}{c}6,5534^{*} \\
(0,0000)\end{array}$ & $I(0)$ \\
\hline pnas & $\begin{array}{r}-252,0000^{*} \\
(0,0000)\end{array}$ & $\begin{array}{c}-0,0868 \\
(0,4654)\end{array}$ & $\begin{array}{r}-46,4120^{*} \\
(0,0000)\end{array}$ & $\begin{array}{l}23,4122^{*} \\
(0,0000)\end{array}$ & $\begin{array}{l}67,2497^{*} \\
(0,0000)\end{array}$ & $I(0)$ \\
\hline
\end{tabular}

Fonte: Elaboração dos autores com aplicação do programa Stata 13.0.

Nota: $\left({ }^{*}\right)$ significante a $1 \% ;\left(^{* *}\right)$ significante a $5 \% ;\left(^{* * *}\right)$ significante a $10 \%$. (1) Os valores-p estão entre parênteses. As probabilidades para os testes de Fisher são computadas usando-se uma distribuição assintótica Qui-quadrado. Os demais testes assumem

normalidade assintótica. (2) Hipótese nula: raiz unitária (assume processo de raiz unitária comum). (3) Hipótese nula: raiz unitária (assume processo de raiz unitária individual). (4) A conclusão foi feita com a maioria dos testes. (5) A variável distcap é constante dentro de cada cross-section, ou seja, a distância do município em relação à capital não muda ao longo do tempo. Nesse sentido, não é possível inferir testes de raiz unitária sobre essa variável. (6) A variável reg é uma dummy, impossibilitando assim, a realização de testes de raiz unitária sobre a mesma. 
Tabela 5: Testes de raiz unitária (continuação)

\begin{tabular}{|c|c|c|c|c|c|c|}
\hline Variáveis & $\begin{array}{l}\text { Levin, Lin } \\
\& \text { Chu t } \mathbf{t}^{(2)}\end{array}$ & $\begin{array}{c}\text { Breitung } \\
\text {-stat }^{(2)}\end{array}$ & $\begin{array}{c}\text { Im, Pesaran, } \\
\text { Shin } W \text {-stat } \\
\end{array}$ & $\begin{array}{l}\text { ADF-Fisher } \\
\text { Chi-square }^{(3)}\end{array}$ & $\begin{array}{c}\text { PP-Fisher } \\
\text { Chi-square }^{(3)}\end{array}$ & Conclusão $^{(4)}$ \\
\hline \multicolumn{7}{|c|}{ Com Intercepto e Tendências Individuais ${ }^{(1)}$} \\
\hline txdesm & $\begin{array}{r}-1.100,0000^{*} \\
(0,0000)\end{array}$ & $\begin{array}{c}16,7654 \\
(1,0000)\end{array}$ & $\begin{array}{r}-500,0000^{*} \\
(0,0000)\end{array}$ & $\begin{array}{r}135,1145^{*} \\
(0,0000)\end{array}$ & $\begin{array}{r}803,7214^{*} \\
(0,0000)\end{array}$ & $I(0)$ \\
\hline efetbova & $\begin{array}{r}-80,1707^{*} \\
(0,0000)\end{array}$ & $\begin{array}{l}1,0039 \\
(0,8423)\end{array}$ & $\begin{array}{r}-8,1808^{*} \\
(0,0000)\end{array}$ & $\begin{array}{l}26,8748^{*} \\
(0,0000)\end{array}$ & $\begin{array}{l}33,6342^{*} \\
(0,0000)\end{array}$ & $I(0)$ \\
\hline cultperm & $\begin{array}{r}-78,4151^{*} \\
(0,0000)\end{array}$ & $\begin{array}{c}3,8203 \\
(0,9999)\end{array}$ & $\begin{array}{r}-6,7829^{*} \\
(0,0000)\end{array}$ & $\begin{array}{l}36,5162^{*} \\
(0,0000)\end{array}$ & $\begin{array}{l}22,5202^{*} \\
(0,0000)\end{array}$ & $I(0)$ \\
\hline culttemp & $\begin{array}{r}-53,3482^{*} \\
(0,0000)\end{array}$ & $\begin{array}{r}-8,8526^{*} \\
(0,0000)\end{array}$ & $\begin{array}{r}-8,3002^{*} \\
(0,0000)\end{array}$ & $\begin{array}{l}30,0243^{*} \\
(0,0000)\end{array}$ & $\begin{array}{l}18,0891^{*} \\
(0,0000)\end{array}$ & $I(0)$ \\
\hline pib & $\begin{array}{r}-49,8753^{*} \\
(0,0000)\end{array}$ & $\begin{array}{c}-0,8971 \\
(0,1848)\end{array}$ & $\begin{array}{r}-8,7377^{*} \\
(0,0000)\end{array}$ & $\begin{array}{l}26,7585^{*} \\
(0,0000)\end{array}$ & $\begin{array}{l}24,1103^{*} \\
(0,0000)\end{array}$ & $I(0)$ \\
\hline dens & $\begin{array}{r}-42,6231^{*} \\
(0,0000)\end{array}$ & $\begin{array}{l}16,6202 \\
(1,0000)\end{array}$ & $\begin{array}{l}14,9268 \\
(1,0000)\end{array}$ & $\begin{array}{r}-11,5778 \\
(1,0000)\end{array}$ & $\begin{array}{r}-10,2845 \\
(1,0000)\end{array}$ & $I(1)$ \\
\hline$D$ (dens) & $\begin{array}{r}-96,8561^{*} \\
(0,0000)\end{array}$ & $\begin{array}{c}10,4092 \\
(1,0000)\end{array}$ & $\begin{array}{r}-10,9766^{*} \\
(0,0000)\end{array}$ & $\begin{array}{l}12,8318^{*} \\
(0,0000)\end{array}$ & $\begin{array}{l}28,0975^{*} \\
(0,0000)\end{array}$ & $I(1)$ \\
\hline fam & $\begin{array}{r}140,0000^{*} \\
(0,0000)\end{array}$ & $\begin{array}{c}3,9020 \\
(1,0000)\end{array}$ & $\begin{array}{r}-3,0956^{*} \\
(0,0010)\end{array}$ & $\begin{array}{l}9,2503^{*} \\
(0,0000)\end{array}$ & $\begin{array}{r}9,2464^{*} \\
(0,0000)\end{array}$ & $I(0)$ \\
\hline pnas & $\begin{array}{r}-120,0000^{*} \\
(0,0000)\end{array}$ & $\begin{array}{c}3,1910 \\
(1,0000)\end{array}$ & $\begin{array}{c}7,2016 \\
(1,0000)\end{array}$ & $\begin{array}{l}11,2267^{*} \\
(0,0000)\end{array}$ & $\begin{array}{l}29,6584^{*} \\
(0,0000)\end{array}$ & $I(0)$ \\
\hline
\end{tabular}

Nota: $\left({ }^{*}\right)$ significante a $\left.1 \% \cdot{ }^{* *}\right)$ significante a $\left.5 \% \cdot{ }^{* * *}\right)$ significante a $10 \%$. (1) Os valores-p estão entre parênteses. As probabilidades para os testes de Fisher são computadas usando-se uma distribuição assintótica Qui-quadrado. Os demais testes assumem normalidade assintótica. (2) Hipótese nula: raiz unitária (assume processo de raiz unitária comum). (3) Hipótese nula: raiz unitária (assume processo de raiz unitária individual). (4) A conclusão foi feita com a maioria dos testes. (5) A variável distcap é constante dentro de cada

cross-section, ou seja, a distância do município em relação a capital não muda ao longo do tempo, nesse sentido, não é possível inferir testes de raiz unitária sobre essa variável. (6) A variável reg é uma dummy, impossibilitando assim, a realização de testes de raiz unitária sobre a mesma. 
Tabela 6: Resultado modelo em painel por MQO e Within Groups

\begin{tabular}{|c|c|c|c|}
\hline Varáveis & Coeficientes & Varáveis & Coeficientes \\
\hline txdesm $m_{i, t-1}$ & $\begin{array}{r}0,9977^{*} \\
(0,0009)\end{array}$ & txdesm $_{i, t-1}$ & $\begin{array}{r}0,7235^{*} \\
(0,0187)\end{array}$ \\
\hline reg & $\begin{array}{r}-0,0127^{*} \\
(0,0029)\end{array}$ & reg & $\begin{array}{r}-0,0030^{*} \\
(0,0018)\end{array}$ \\
\hline efetbova & $\begin{array}{r}-0,0035^{*} \\
(0,0004)\end{array}$ & efetbova & $\begin{array}{c}0,0031^{* *} \\
(0,0014)\end{array}$ \\
\hline cultperm & $\begin{array}{r}0,0021^{*} \\
(0,0009)\end{array}$ & cultperm & $\begin{array}{c}-0,0001 \\
(0,0006)\end{array}$ \\
\hline cultemp & $\begin{array}{r}0,0009^{*} \\
(0,0005)\end{array}$ & cultemp & $\begin{array}{c}0,0019 \\
(0,0012)\end{array}$ \\
\hline pib & $\begin{array}{c}0,0035 \\
(0,0043)\end{array}$ & pib & $\begin{array}{c}-0,0025 \\
(0,0040)\end{array}$ \\
\hline$p i b_{i, t-1}$ & $\begin{array}{c}0,0057 \\
(0,0048)\end{array}$ & $p i b_{i, t-1}$ & $\begin{array}{c}0,0013 \\
(0,0047)\end{array}$ \\
\hline$p i b_{i, t-2}$ & $\begin{array}{c}-0,0083^{* *} \\
(0,0041)\end{array}$ & $p i b_{i, t-2}$ & $\begin{array}{c}0,0027 \\
(0,0043)\end{array}$ \\
\hline fam & $\begin{array}{r}-0,0008 \\
(0,0006)\end{array}$ & fam & $\begin{array}{r}0,0173^{*} \\
(0,0060)\end{array}$ \\
\hline pnas & $\begin{array}{r}0,0037^{*} \\
(0,0004)\end{array}$ & pnas & $\begin{array}{r}-0,0165^{*} \\
(0,0060)\end{array}$ \\
\hline distcap & $\begin{array}{c}0,0003 \\
(0,0006)\end{array}$ & distcap & $\begin{array}{c}-0,0123 \\
(0,0101)\end{array}$ \\
\hline dens & $\begin{array}{c}0,0032 \\
(0,0034)\end{array}$ & dens & $\begin{array}{l}-0,0106^{* *} \\
(0,0056)\end{array}$ \\
\hline const & $\begin{array}{r}0,0463^{*} \\
(0,0086) \\
\end{array}$ & const & $\begin{array}{r}1,6845^{*} \\
(0,1062) \\
\end{array}$ \\
\hline$N$ & 4323 & $N$ & 4323 \\
\hline$R^{2}$ & 0,9993 & $R^{2}-$ within & 0,8753 \\
\hline Prob $>F$ & 0,0000 & $\begin{array}{c}R^{2}-\text { between } \\
R^{2}-\text { overall } \\
\text { Prob }>F\end{array}$ & $\begin{array}{l}0,9991 \\
0,9985 \\
0,0000\end{array}$ \\
\hline
\end{tabular}

Fonte: Elaboração dos autores com aplicação do programa Stata 13.0. Nota: $\left({ }^{*}\right)$ significante a $1 \% ;\left({ }^{* *}\right)$ significante a $5 \% ;\left({ }^{* * *}\right)$ significante a $10 \%$. Os modelos estimados com variáveis dummies de tempo, omitidas na tabela, foram todas significantes. Os erros-padrão são robustos a heterocedasticidade. 
